\title{
Estudio de la Expresión de los Receptores de Progesterona y Estrógeno en el Endometrio de Ovejas Alimentadas con Dieta Normal y Dieta Suplementada
}

\author{
Study of the Expression of Progesterone Receptors in the \\ Endometrium of Ewes with Normal and Supplementary Diet \\ *;**Adriana Vasconcellos C.; **Marco Paredes H.; "*Daniela Núñez R.; \\ ${ }^{* *}$ Eduardo Barrientos V.; ${ }^{* *}$ Yoselyn Olmazábal S. \& ${ }^{* *}$ Javiera Navarrete V.
}

\begin{abstract}
VASCONCELLOS, C. A.; PAREDES, H. M.; NÚÑEZ, R. D.; BARRIENTOS, B. E.; OLMAZÁBAL, S. Y. \& NAVARRETE, V. J. Estudio de la expresión de los receptores de progesterona y estrógeno en el endometrio de ovejas alimentadas con dieta normal y dieta suplementada. Int. J. Morphol., 28(2):575-581, 2010.
\end{abstract}

RESUMEN: La influencia de la nutrición sobre la reproducción en ovinos es compleja y los resultados observados son variables. Planes nutricionales bajos pueden ser causa de una reducción de la sensibilidad del endometrio a la progesterona lo que afecta el desarrollo morfofuncional del endometrio en estadios tempranos de la preñez y por lo tanto va en directo detrimento de la sobrevida del embrión. La progesterona y los estrógenos actúan a través de receptores intracelulares específicos que median su efecto fisiológico. Por lo tanto el nivel de expresión de estos receptores es fundamental para el efecto hormonal. El objetivo del presente estudio fue analizar en forma conjunta la expresión de receptores de progesterona (RP) y estrógeno (RE), en el endometrio de ovejas en ciclo alimentadas con dieta suplementada y dieta normal. La expresión de la proteína receptora como del transcrito de ambos receptores se detectó mediante análisis inmunohistoquímico y RT-PCR en Tiempo Real. Los resultados muestran expresión inmunohistoquímica contra ambos receptores en zonas glándulares y carunculares, destacándose una intensa inmunorreacción en núcleo de células estromales y del epitelio glandular. Se detectó mayor expresión del transcrito de ambos receptores en ovejas alimentadas con suplemento respecto a las que no recibieron suplemento alimenticio.

PALABRAS CLAVE: Oveja criolla Araucana, Sistema reproductor, Alimentación de ovejas.

\section{INTRODUCCIÓN}

La nutrición afecta a los ovinos desde la gametogénesis a la preñez, lo que los hace sensibles a cambios nutricionales (Scaramuzzi et al., 2006). Desde el punto de vista reproductivo, el efecto del plano nutricional sobre la prolificidad de ovejas ha sido ampliamente estudiado, sin embargo, aun existen pocos reportes que vinculen el efecto de la alimentación sobre la expresión de receptores de hormonas esteroidales, cuya presencia en las células de diversos órganos del sistema reproductor es clave para el desarrollo de respuestas fisiológicas apropiadas (Spenser \& Bazer, 1995; Meikle et al., 2004). Algunos datos relacionados con planos nutritivos y expresión de receptores han sido aportados por Lozano et al., (1997), los cuales indican que la baja nutrición se relaciona de forma significativa con la disminu- ción del efecto de la progesterona a nivel endometrial, lo que se debe posiblemente a una disminución en la cantidad de receptores. Generalmente los estudios han sido hechos en ovejas sub-nutridas utilizando controles mantenidos con alimentación normal (Sosa et al., 2004). No obstante, no se ha comparado los efectos de planos nutricionales con elevados niveles de carbohidratos y proteína sobre la capacidad reproductiva en ovejas. En ovejas sometidas a un plano nutricional bajo se ha visto reducción de la sensibilidad del endometrio a la progesterona debido a la reducción de sus receptores, lo que impide un adecuado desarrollo uterino, afectando la implantación y posterior sobrevida del embrión (Lozano et al., 1997; Sosa et al., 2003; Abecia et al., 2006). Tanto los estrógenos como la progesterona interactúa con su re-

\footnotetext{
* Depto. de Ciencias Básicas Facultad de Medicina, Universidad de La Fontera, Temuco, Chile

** LIMBA, Laboratorio de Investigación en Biotecnología Animal, Universidad de La Frontera, Chile.
} 
ceptor en las células endometriales y la respuesta celular depende de la cantidad de receptores presentes (Clark et al., 1992; Clark \& Mani, 1994). Por lo tanto, factores que modifican las concentraciones de receptores pueden controlar la acción hormonal a nivel reproductivo. De este modo el propósito de nuestro trabajo fue evaluar comparativamente en el mismo tejido la expresión inmunohistoquímica y transcripciónal de los receptores de estrógeno y progesterona en endometrio de ovejas Criollas Araucanas mantenidas con alimentación estándar y suplementada.

\section{MATERIAL Y MÉTODO}

Se utilizaron 8 ovejas Criolla Araucana de 2 a 4 años de edad, mantenidas en el Campo Experimental Maquehue (Región de la Araucanía), las que se dividieron en dos grupos iguales. Ambos grupos fueron mantenidos a base de pradera mixta con ballica perenne y trébol blanco (dieta estándar). Adicionalmente uno de los grupos tuvo acceso diariamente después del pastoreo a una suplementación con 250 g/día de grano de avena y $30 \mathrm{~g} /$ día de proteína cruda (dieta suplementada).

La etapa del ciclo estral fue confirmada por anamnesis, estudio histológico y medición de concentraciones de progesterona y estrógeno en sangre (datos no mostrados). Después del sacrificio se extrajo el sistema reproductor, separando inmediatamente los dos cuernos uterinos, unos de los cuales se fijó en Bouin acuoso, para su estudio inmunohistoquímico y el otro se congeló en nitrógeno líquido para extracción de ARN.

Análisis inmunohistoquímico. Las muestras fijadas se incluyeron en Paraplast (Merck, Alemania) y posteriormente se prepararon cortes de 5 micras a partir del tejido incluido. Los cortes se procesaron eliminado el Paraplast con xilol y luego se hidrataron mediante incubación en una batería de concentración decreciente de etanol. Posteriormente, se eliminó la actividad de peroxidasas endógenas incubando con $\mathrm{H}_{2} \mathrm{O}_{2}$ al $3 \%$ en metanol por $10 \mathrm{~min}$. Se lavó luego, dos veces con tampón fosfato salino (PBS) por 5 minutos cada vez y se procedió a incubar los cortes en solución de bloqueo (BSA $1 \%$ y tritón X-100 0,3\%, diluidos en PBS) a temperatura ambiente por 30 minutos. Los cortes se incubaron a continuación conun anticuerpo policlonal anti-RE (H-184; Santa Cruz Biotechnology, USA) y anticuerpo monoclonal anti-RP (NeoMarkers, USA) el primero diluido 1:500 y el segundo 1:100 en solución de bloqueo durante 12 horas a temperatura ambiente. Posteriormente los cortes se lavaron 3 veces por 5 minutos cada vez con PBS. En adelante se utilizó el sistema de detección LSABTM Kits (Dako, USA) el cual se basa en el reconocimiento del primer anticuerpo por un segundo anticuerpo anti-IgG conjugado a biotina el cual interacciona específicamente con el complejo estreptoavidina conjugada a peroxidasa. Los lavados y tiempos de incubación se efectuaron de acuerdo a las instrucciones del fabricante del kit. El revelado se realizó incubando en solución DAB $(0,5 \%)$ y perhidrol $(1 \mathrm{ml} / \mathrm{ml})$ en PBS, a temperatura ambiente por 5 a 10 min. La muestra histológica se lavó con agua destilada y seguidamente se tiño para contraste nuclear, con hematoxilina. Seguidamente, se deshidrató en una batería creciente de etanol y se diafanizó con xilol. Finalmente los cortes se montaron con resina Entellan (Merck). El análisis microscópico y captura de imágenes digitales se efectuó utilizando un microscopio Leitz, Laborlux 12.

Análisis de expresión de los transcritos de RE y RP por RT-PCR en tiempo real. El nivel de expresión de los transcritos de RE y RP en el endometrio de oveja, se evaluó por medio de RT-PCR en tiempo real mediante el método "Comparative $\mathrm{Ct}(\Delta \mathrm{Ct})$ " implementado en el sistema de amplificación en tiempo real "Step One" de Applied Biosystem (USA). Para esto, se extrajo inicialmente RNA a partir de cuerno uterino según metodología descrita por Chomczynski y Sacchi, (1986). Para estimar la concentración del RNA obtenido se utilizó la ecuación [RNA] = OD260 x FD x $40 \mu \mathrm{g} / \mu \mathrm{l}$, donde FD es el factor de dilución utilizado y OD260 la absorbancia medida a $260 \mathrm{~nm}$. Mientras que la pureza se evaluó mediante la razón de absorbancia OD260/OD280, considerado valores de de 1,8 a 2 como buena estimación de pureza. El RNA obtenido se utilizó para preparar ADN complementario (cDNA) mediante el uso del kit "High Capacity RNA to cDNA kit" (Applied Biosystems, USA). Para ello, se utilizaron $2 \mu \mathrm{g}$ de RNA total, el cual se mezcló con $5 \mu \mathrm{l}$ de tampón RT $2 \mathrm{X}$ y $0.5 \mu \mathrm{l}$ del de enzimas 20X (transcriptasa reversa y RNasa $\mathrm{H}$ ) provistas por el fabricante del kit. La mezcla de reacción se completó a $10 \mu \mathrm{l}$ de volumen final con agua ultrapura y se incubó a $37^{\circ} \mathrm{C}$ por 60 minutos, finalmente reacción de trascripción se detuvo incubando a $90^{\circ} \mathrm{C}$ por 5 minutos. El cDNA obtenido se utilizó como templado para la detección y amplificación específica de RE, RP y $\beta$-actina cuya expresión constitutiva se utilizó como control endógeno referencial para la cuantificación relativa. Los cDNAs de RE y RP se amplificaron por PCR en tiempo real, mezclando $1 \mu \mathrm{l}$ del respectivo cDNA con $10 \mathrm{ml}$ del tampón de reacción Power SYBR Green PCR Master Mix 2X (Applied Biosystem), $7 \mathrm{ml} \mathrm{de}$ agua ultrapura y $1 \mathrm{ml}(10 \mathrm{mM})$ de cada uno del par de partidores RE-S/RE-A (Tabla 1) o RP-S/RP-A (Tabla1) ambos pares concentrados a $10 \mathrm{mM}$. El cDNA de $\beta$-actina se amplificó con mezclas de reacciones similares a las descritas para RE y RP, pero utilizando el par de partidores específicos OB-A/OB-S a 10mM cada uno (Tabla I). Todas las reacciones se realizaron en un volumen de reacción final 
de $20 \mathrm{ml}$. Las condiciones térmicas de amplificación para los tres genes fueron similares y se programaron con un ciclo inicial de 10 minutos a $95^{\circ} \mathrm{C}$, seguido por 45 ciclos compuestos cada uno por una denaturación a $95^{\circ} \mathrm{C}$ por 20 segundos, hibridación a $60^{\circ} \mathrm{C}$ por 20 segundos y extensión a $72^{\circ} \mathrm{C}$ por 20 segundos. Se programó al término de los 45 ciclos de amplificación, un ciclo para el análisis de las temperaturas de fusión (melting) de los amplicones, lo cual permitió evaluar la especificidad de la reacción de amplificación y descartar de este modo el efecto de productos no específicos sobre la cuantificación.
Obtención de partidores para amplificación de RE y RP por RT-PCR en Tiempo Real. Los partidores utilizados para el análisis por PCR en tiempo real (Tabla I) se derivaron a partir de la secuencias del cDNA del RE de oveja disponible en la base de datos GenBank disponible en el servidor web del National Center for Biotechnology Information (http://www.ncbi.nlm.nih.gov). Los partidores utilizados para amplificar el cDNA de $\beta$-actina (Tabla I) se obtuvieron de Dzidic et al., (2004). El diseño bioinformático de los partidores se efectuó con el programa "Primer 3" (http://primer3.sourceforge.net/).

Tabla I. Secuencias de olígonucleótidos utilizados como partidores para las reacciones de amplificación del cDNA del receptor de estrógeno (RE-S/ RE-A), receptor de progesterona (RP-S/ RP-A) y $\beta$-actina (OB-S/ OB-A)

\begin{tabular}{ll}
\hline Secuencias de partidores & $\begin{array}{l}\mathrm{N}^{\circ} \text { aces so a Gen Bank } \\
\text { Fuente bibliográfica }\end{array}$ \\
\hline $\begin{array}{l}\text { RE-S: CTCCACGATCAAGTCCACCT } \\
\text { RE-A: ACGGAACCGAGACGATGTAG }\end{array}$ & A 933393 \\
& \\
RP-A: TGTGCTGGAAGAAACGATTG & Z663393 \\
RP-S: TAGGGCTTGGCTTTCATTTG & Z6655.1 \\
& \\
OB-S: AACTCCATCATGAAGTGTGAC & (Dzidic et al, 2004). \\
OB-A: GATCCACATCTGCTGGAAGG & (Dzidic et al, 2004) \\
\hline
\end{tabular}

\section{RESULTADOS}

El análisis inmunohistoquímico de los receptores de estrógeno y progesterona en tejido endometrial de ovejas adultas mantenidas con y sin suplemento alimenticio, indica la existencia de reacción inmunohistoquímica contra ambos receptores en ambos grupos de ovejas (Figs. 1 y 2). Particularmente las señales inmunoreactivas se destacan a nivel nuclear en células de las glándulas endometriales y células estromales ubicadas en las zonas glandulares carunculares del endometrio (Figs. 1 y 2). También se observa inmunorreacción parcial en células del epitelio de revestimiento (Figs. 1A y 2A). Se observa mayor cantidad de células inmunoreactivas como también mayor intensidad de la marca de ambos receptores en tejido endometrial de ovejas con suplementación respecto a las que se alimentaron con dieta estándar (Figs. 1 y 2). Se detecto el transcrito de RP y RE en RNA total extraído del endometrio de ovejas alimentadas con dieta estándar como también con dieta suplementadas (Fig. 3).

La evaluación del nivel de expresión de los transcritos de RE y RP en muestras de tejido endometrial similares a las utilizadas para la evaluación inmunohistoquímica indica que los transcritos de RE y RP se expresan a un mayor nivel en tejido endometrial de ovejas que fueron alimentadas con suplementos alimenticios (Fig. 4).

\section{DISCUSIÓN}

La distribución celular de la expresión inmunohistoquímica de los receptores de estrógeno y progesterona en endometrio descrita en este trabajo refleja el efecto de las hormonas esteroidales sobre el desarrollo morfofuncional del endometrio. Tanto en las áreas carunculares como intercarunculares o glandulares se detectó reacción inmunohistoquímica tal como lo descrito por Meikle et al., (2001; 2004) y Vascocellos et al., 2008, 2009) el cual detecto estos receptores en diversos órganos del tracto genital de oveja en distintas etapas de la vida reproductiva. Sin embargo en este trabajo no se evaluó el efecto de la alimentación sobre el nivel de expresión de es- 

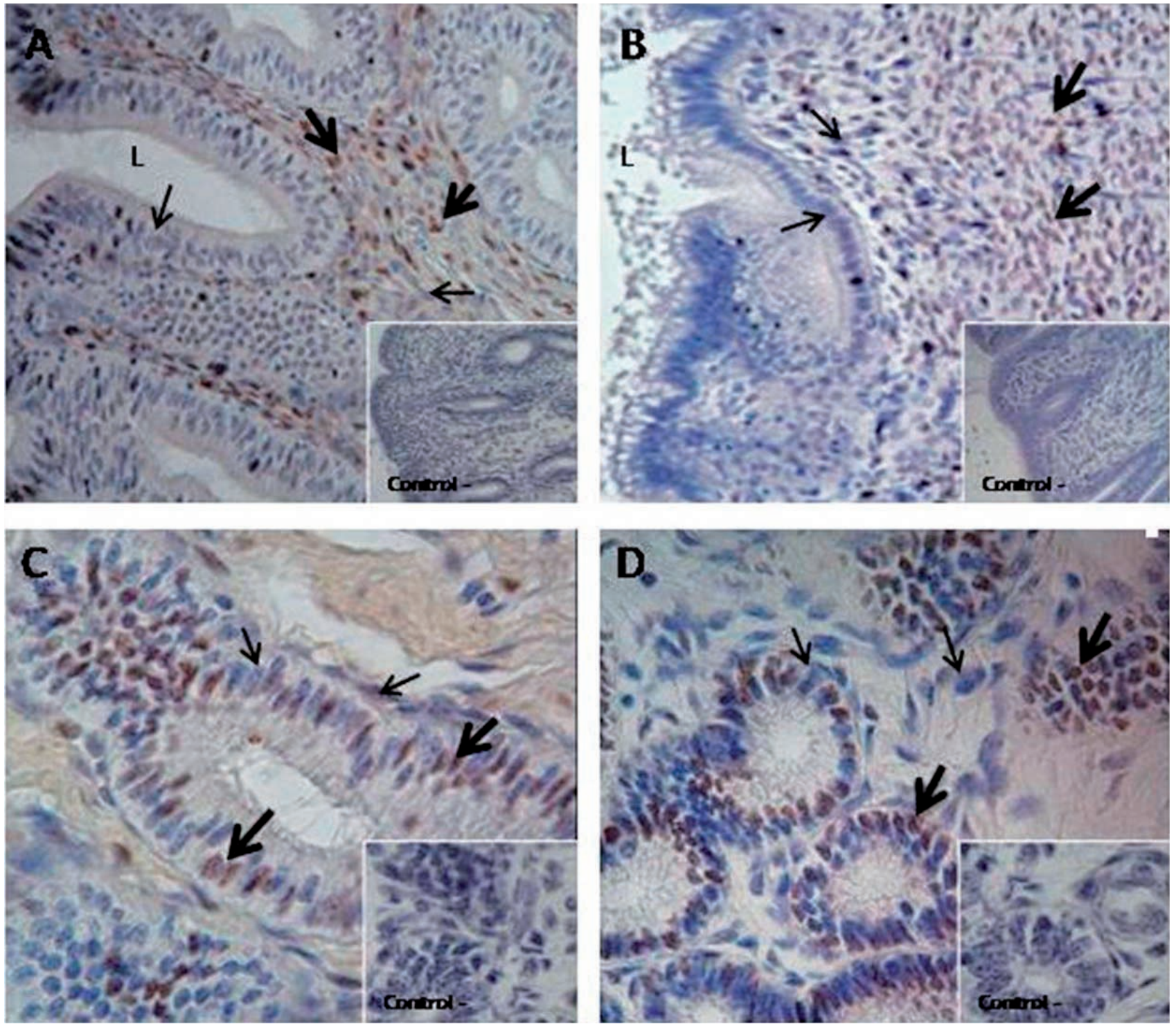

Fig. 1. Expresión inmunohistoquímica del RE en endometrio de ovejas con dieta no suplementada (A y C) y suplementada (B y D). Se destaca (flecha gruesa) inmunorreacción en células estromales (A y B) y en epitelio glandular (C y D). También se indica (flecha delgada) ausencia de inmunorreactividad en epitelio endometrial y algunas células del epitelio glandular. Figura 1 A y 1 B (400X), Figura $1 \mathrm{C}$ y $1 \mathrm{D}(1000 \mathrm{X})$.

tos receptores. No existe mucha evidencia del efecto de la nutrición sobre expresión de RE y RP en ovejas, lo cual dificulta el análisis comparativo, sin embargo se ha estudiado el efecto de la nutrición sobre la síntesis de FSH y LH encontrándose que el nivel de estas hormonas en la sangre de ovejas se correlaciona con la concentración de leptinas circulantes (Scaramuzzi et al., 2006), hormona que se encuentra en mayor cantidad en animales adecuadamente nutridos (Scaramuzzi et al.). De este modo es posible suponer que el aumento del nivel de LH y FSH circulante como consecuencia de una mejor nutrición podría estar estimulando a nivel endometrial el aumento de la expresión de RE y esto a su vez determinando una mayor expresión de RP. Además, es interesante señalar que estudios de Sosa et al., (2004) muestran que el factor de crecimiento insulínico tipo I (IGF-I), disminuye su concentración en la sangre de ovejas deficientemente nutridas. Lo cual sugiere que en ovejas alimentadas con dieta suplementada este factor podría aumentar como efecto de la dieta. De este modo existirá un mayor estimulo a nivel endometrial para la expresión de receptores de estrógeno, lo cual podría correlacionarse con el mayor nivel de expresión de este receptor descrito en nuestro trabajo para el grupo de ovejas mantenidas con alimentación suplementada respecto a las menos nutridas. 

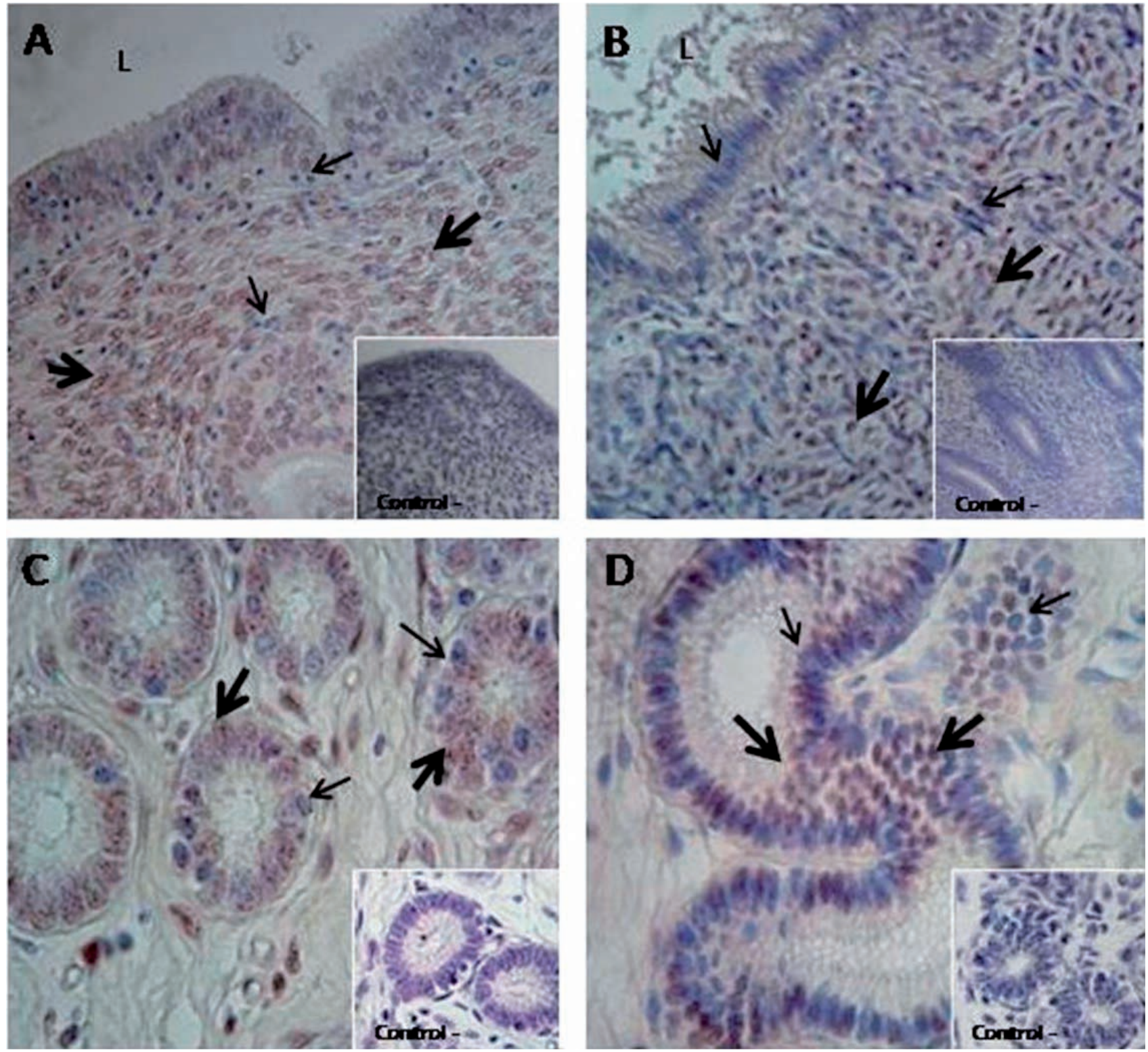

Fig. 2. Expresión inmunohistoquímica del RP en endometrio de ovejas con dieta no suplementada (A y C) y suplementada (B y D). Se destaca (flecha gruesa) inmunoreacción en células estromales (A y B) y en epitelio glandular (C y D). La flecha negra delgada indica ausencia de inmunoreactividad en epitelio endometrial y algunas células del epitelio glandular. Figura 2 A y 2 B (400X), Figura 2 C y D (1000X).

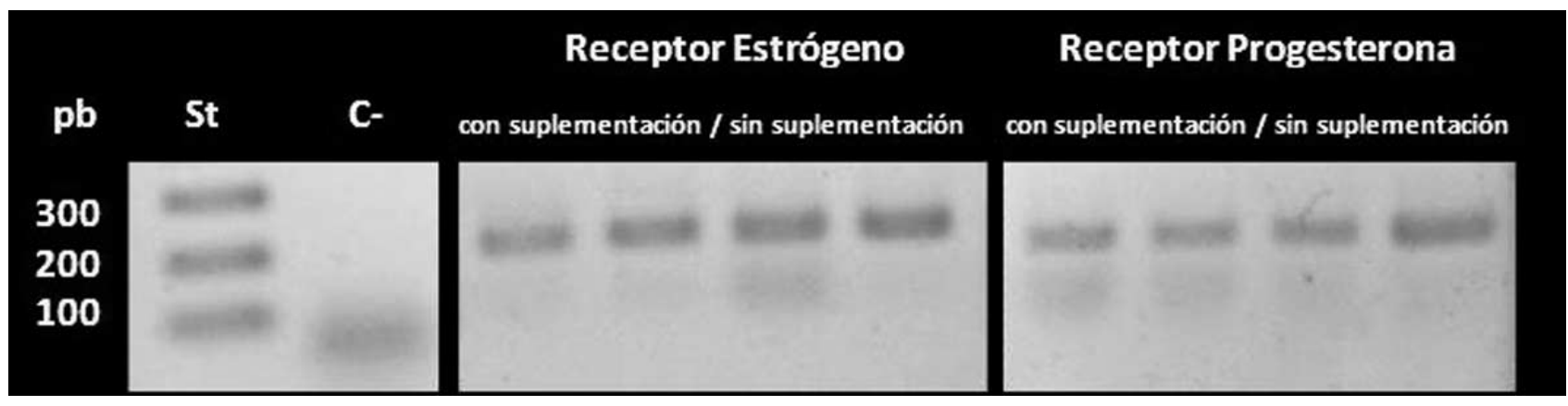

Fig. 3. Detección de los transcritos de RE y RP por RT-PCR, teñidos con bromuro de etidio $(0,5 \mathrm{mg} / \mathrm{mg})$ y visualizados en gel de agarosa al $1,8 \%$. 

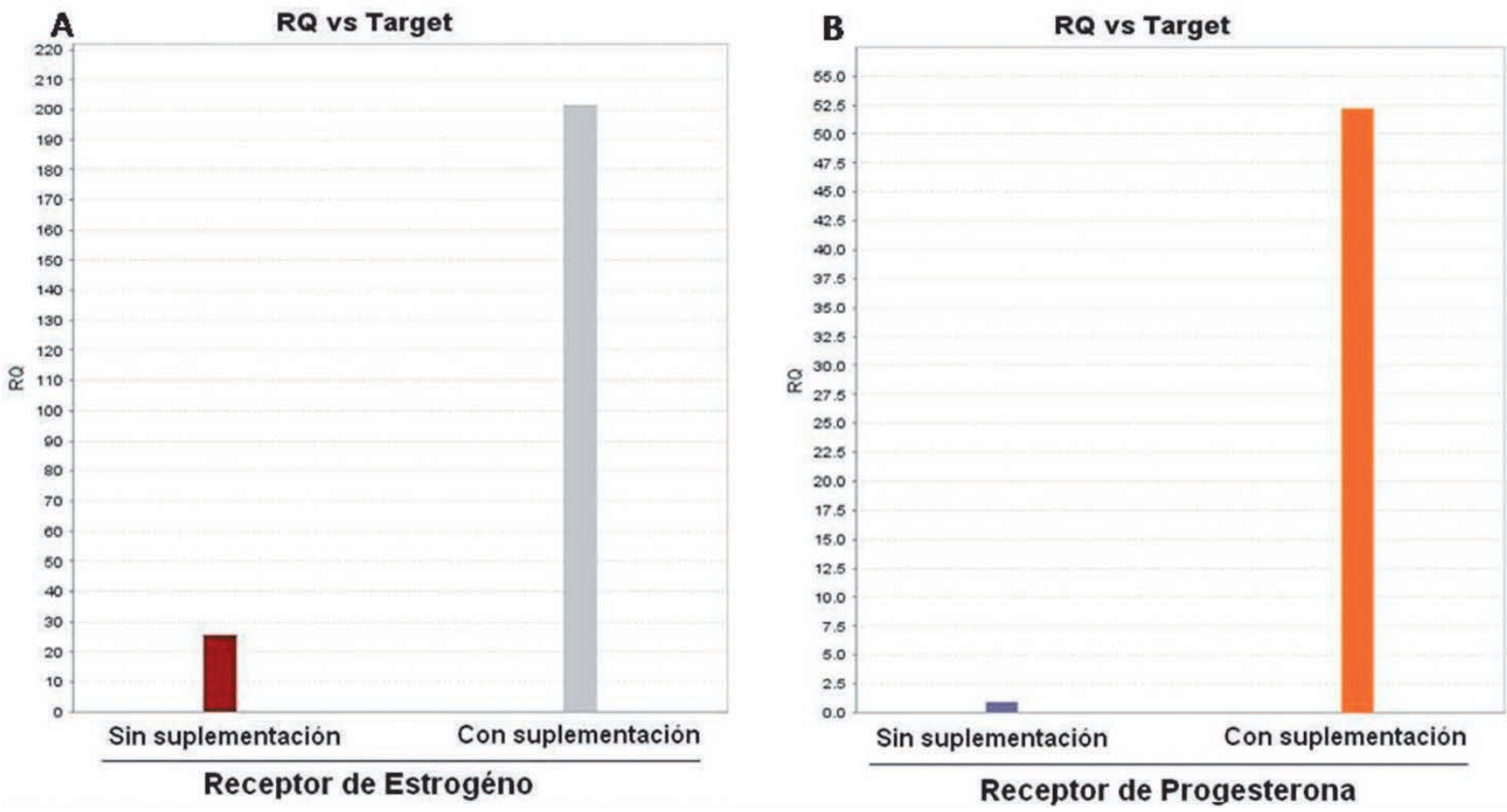

Fig. 4.Representación grafica del nivel de expresión de los transcritos de RE (A) y RP (B) en endometrio de ovejas suplementadas y no suplementadas. El análisis de expresión se efectuó mediante RT-PCR en tiempo real utilizando la expresión del gen $\beta$-actina como control endógeno.

\section{CONCLUSIÓN}

Se concluye que tanto la expresión inmunohistoquímica como transcripciónal de los RE y RP es mayor en endometrio de ovejas que recibieron dietas suplementadas respecto a ovejas mantenidas con dieta estándar.

\section{AGRADECIMIENTOS}

Se agradece a la Dirección de Investigación de la Universidad de la Frontera, Temuco, Chile, por el apoyo económico entregado mediante el Proyecto DIUFRO 1070017

VASCONCELLOS, C. A.; PAREDES, H. M.; NÚÑEZ, R. D.; BARRIENTOS, B. E.; OLMAZÁBAL, S. Y. \& NAVARRETE, V. J. Estudio de la expresión de los receptores de progesterona y estrógeno en el endometrio de ovejas con dieta normal y dieta suplementada. Int. J. Morphol., 28(2):575-581, 2010.

SUMMARY: The influence of nutrition on reproduction in sheep is complex and the reported results are variable. Low nutritional programs can cause a reduction in the sensitivity of the endometrium to progesterone which affects morphofunctional development of the endometrium in early stages of pregnancy and therefore is in direct expense of the survival of the embryo. Progesterone and estrogens act through specific intracellular receptors that mediate its physiological effect. Therefore the level of expression of these receptors is essential for the hormonal effect. The aim of this study was to analyze the expression of progesterone receptors (PR) and estrogen (ER) in the endometrium of sheep supplemented diet cycle and fed normal diet. The expression of the receptor protein and the transcript of both receptors was detected by immunohistochemistry and RT-PCR Real Time. The results show immunohistochemical expression against both receptors in caruncular and glandular areas, highlighting an intense immunoreaction in the nucleus of stromal cells and glandular epithelium. Were detected increased expression of the transcript of both receptors in sheep fed on the supplement that did not receive food supplement. We discuss the possible use of this information for applications in breeding programs in sheep breeding.

KEY WORDS: Oveja criolla Araucana; Reproductive system; Sheep food. 
VASCONCELLOS, C. A.; PAREDES, H. M.; NÚÑEZ, R. D.; BARRIENTOS, B. E.; OLMAZÁBAL, S. Y. \& NAVARRETE, V. J. Estudio de la expresión de los receptores de progesterona y estrógeno en el endometrio de ovejas alimentadas con dieta normal y dieta suplementada. Int. J. Morphol., 28(2):575-581, 2010.

\section{REFERENCIAS BIBLIOGRÁFICAS}

Abecia J.; Sosa, C.; Forcada, F. \& Meikle A. The effect of undernutrition on the establishment of pregnancy in the ewe. Reprod. Nutr. Dev., 46: 367-78, 2006.

Clark, J.; Schrader, W. \& O'Malley, B. Mechanisms of action of steroid hormones. En Williams Textbook of Endocrinology. Ed. W. B. Saunders, 1992. Pp. 35-90.

Clark, J. \& Mani, S. Actions of ovarian steroid hormones. In Knobil E., Neill J D. (Eds). The physiology of Reproduction. Raven Press, New York, 1994. Pp. 10111059.

Chomczynski, P. \& Sacchi, N. Single-step method of rna isolation by acid guanidinium thiocyanate-phenolchloroform extraction. Anal biochem., 162:156-59, 1987.

Lozano, J.; Abecia, J.; Forcada, F.; Zarazaga, L. \& Alfaro B. Effect of undernutrition on the distribution of progesterona in the uturus of ewes during the luteal phase of the estrous cycle. Theriogenology, 49: 539-46, 1997.

Meikle, A.; Garófalo, E.; Tasende, C.; Rodríguez-Piñón \& Shalin, L. Regulation by gonadal steroids of estrogen and progesterona receptors along the reproductive tract in female lambs. Acta Vet. Scand., 42:161-9, 2001.

Meikle, A.; Tasende, C.; Sosa, C. \& Garófalo, E. The rol of sex steroid receptors in sheep female reproductive physiology. Reprod. Nutr. Dev., 16: 385-94, 2004.

Scaramuzzi, R.; Campbell, B.; Downing, J.; Kendall, N.; Khalid, M.; Muñoz-Gutiérrez, M. \& Somchit, A. A review of the effects of supplementary nutrition in the concentrations of reproductive and metabolic hormones and the mechanisms that regulate folliculogenesis and ovulation rate. Reprod. Nutr. Dev., 46: 339-54, 2006.

Sosa, C.; Lozano, J.; Viñoles, C.; Acuña, S.; Abecia, J.; Forcada, F.; Fosberg, M. \& Meikle, A. Effect of plane of nutrition on endometrial sex steroid receptor expresión in ewes. Animal Reproduction Science, 84:337-48, 2004.

Spencer, T. \& Bazer, W. Temporal and spatial alterations in uterine estrogen receptor and progesterone receptor gene expression during the estrous cycle and early pregnancy in the ewe. Biol. Reprod., 53:1527-43, 1995.
Vasconcellos, A.; Paredes, M.; Carrasco, J. \& Núñez D. Analisis de la Expresión de receptores de estrógenos y progesterona en el endometrio de Ovejas de las razas Romney Marsh y araucana. Int. J. Morphol., 27(1):97100, 2009.

Vasconcellos, A., Sepúlveda, N., Castillo, J., Rosas, C. Presencia de receptores de Estrógeno y de Progesterona en el Endometrio de ovejas prepúberes. Estudio inmunohistoquímico. Int. J. Morphol., 23 (4):393-6, 2005.

Dirección para correspondencia:

Marco Paredes $\mathrm{H}$.

Facultad de Medicina

Universidad de La Frontera

Casilla 54-D

Temuco - CHILE

Email: mparedes@ufro.cl

Recibido : 24-02-2010

Aceptado: 26-03-2010 
